\title{
RUTGERS UNIVERSITY AND THE "INFORMATION SOCIETY"
}

\author{
BY JOANNE R. EUSTER
}

Dr. Euster is Vice President for Information Services and University Librarian, Rutgers University.

W E ALL have heard a great deal about the "Information Society," and have certainly been heavily affected by it in our work and personal lives. What we are now becoming aware of is the need to make our organizations information organizations-organizations that are not just affected by information, but ones that consciously plan and organize themselves to create, organize and disseminate information to support the organizational mission, which at Rutgers means to support the mission of the University. There is a story I like about the little girl who is carefully drawing a picture; her teacher asks what she is drawing, and the child replies, "I'm drawing a picture of God." To which the teacher responds, "But nobody knows what God looks like!" "Well," says the girl, "They will when I finish!" This is somewhat where Rutgers is in terms of becoming an information organization. In many respects, we at Rutgers are in the forefront, inventing the information future, moving into areas where there are no tried and true models.

"Information Services" as an organizational unit at Rutgers was created only last fall, and at the moment is structured as in Figure I, a fairly traditional organization chart, with computing services as one branch, and libraries as another, and further subdivisions within each. However, we are also aware that there is a tremendous amount of overlap in the functions among the various units; for example, libraries now have all sorts of electronic information resources and computer centers have print libraries. These areas of overlap are not neatly defined; rather they are fuzzy boundaries where the work of academic and administrative computing converge, and where the work of the libraries converges with both of them (Figure 2). In addition, all three have in common their reliance on the electronic communications network that ties them together, and to many of their users.

At the same time, both libraries and computing services are struggling to move beyond their respective origins - computing services in the large

Adapted from remarks delivered March I 3, I 990 to the Senior Vice President and Treasurer's Luncheon, Rutgers University. 


\section{Rutgers University Information Services}

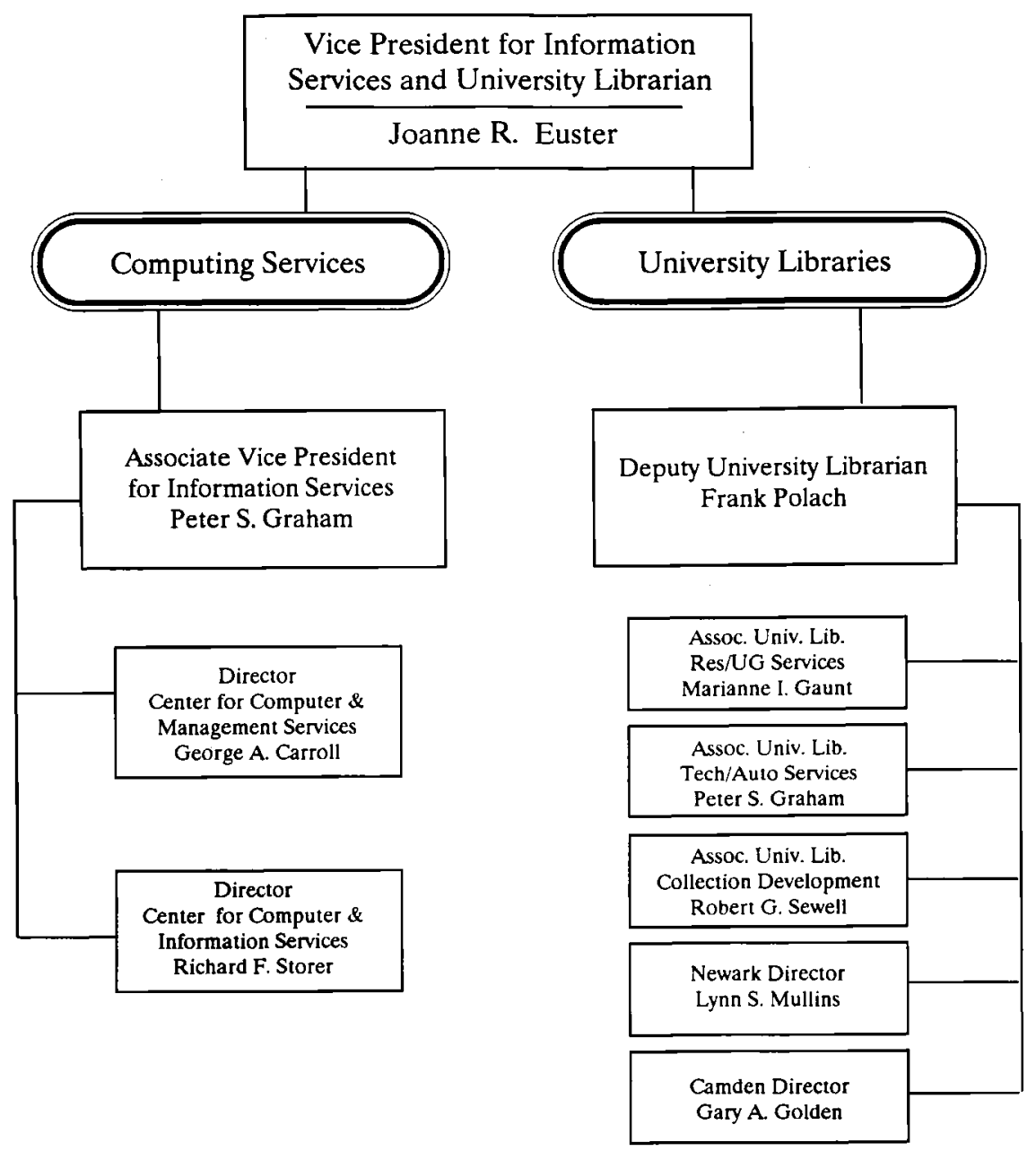

Figure I 
number-crunching computation machines that virtually mandated that all computing be centrally operated and organized, and libraries in huge storehouses of books and other print materials - to a service orientation that focuses on getting to the user what is needed, when and where it is needed, in a form that is most useful to the user.

Thus, another way of looking at the University's information universe is to consider who needs what information. We have been accustomed in libraries - and now I hear the same words in computing circles_- to think-

\section{INFORMATION SERVICES}

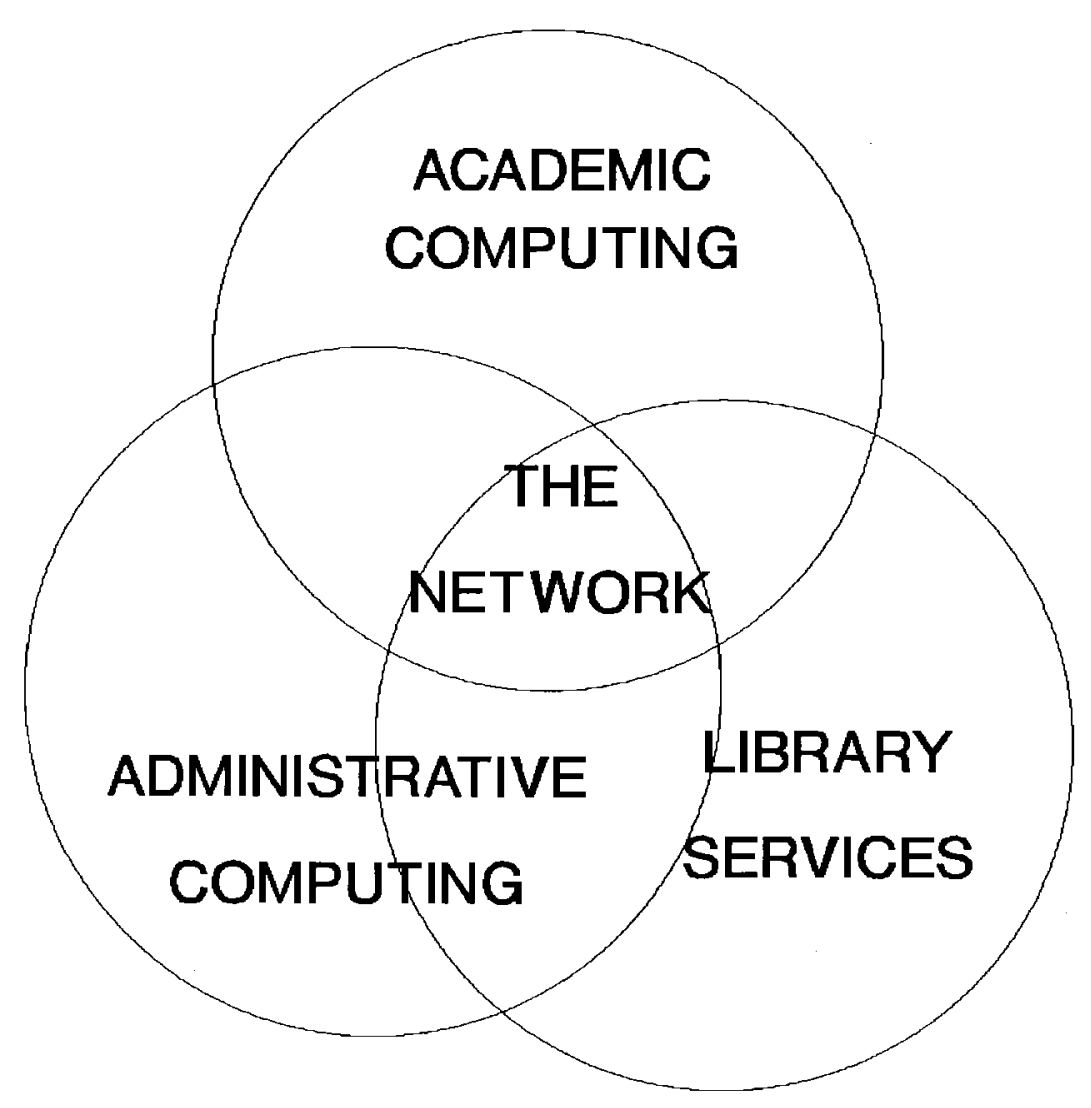

Figure 2 
ing about ourselves as "service organizations." The difficulty is that this service concept has seemed to follow a sort of medical model: the doctor (library, computing service) knows what is good for you and prescribes what you should and can have in the way of treatment (or service). Two things are wrong with this, and those of you who followed the three-part series in the New York Times about the changes in attitudes toward doctors can see what is coming: The supposed expert (librarian, computer analyst) really has to be a partner with the user in deciding what the user needs; in a large sense, the user is the expert on needs. Secondly, the definition of who the provider is keeps shifting; some of the time it is the central computer service, but at other times it is the local office which supplies the information to be gathered and redistributed, in the same form, or in a different form. In the libraries, sometimes the provider is the library, sometimes it is a database housed and managed somewhere else and the library only serves as an intermediary; as scholars increasingly do their work on computers, and libraries make scholarly work available on computers, the libraries can expect to have yet another role as facilitators.

The impetus behind the growth of centralized computing and large centralized library systems was the desire for efficiency. Big machines cost less for the same capacity than dozens of small machines. Centralized library systems reduced duplication of collections and activities. The potential for electronic distribution of information and for accessing and processing it at the desktop has changed that somewhat. However, distribution tends to bring with it proliferation. Some systematic way of maintaining efficiency has to govern distributed systems. My mantra for this is becoming: "Buy it once; create it once; enter it once; just do it once!"

What begins to emerge is a vision of not a single organization, but a single mission, to have both efficiency and information power in the hands of people who need it. The key to making this vision work is connectivity. What is connectivity? In the talks I give, and in the long range plan for the libraries, the idea of the unified system-the Rutgers University Libraries-is used as if the libraries were one large library which just happened to be in I 8 diverse geographic locations. In this model, the "glue" which holds the system together is a sort of "virtual network," partly made up of a shared computer database (the online catalog), partly made up of delivery systems, and partly made up of systemwide policies and understandings so that activities of one library fit into those of another. Similarly, this connectivity is what can make centralized and distributed information processing and use work. Again, it is partly a physical network - wires between campuses, between offices - but it is equally a mat- 
ter of a way of thinking about the university and the way information is shared and used. Some of the necessary mind-set will be codified in policies and procedures. A great deal of the orientation relies on individuals thinking in terms such as: "What information do I need from others to do my job? What information do I have that others need to do their jobs? How can information move among us most effectively?" The key concept is almost certainly trust-treating information as something to be shared and used, not hoarded and doled out grudgingly.

If we are to behave like an information organization, we need to address the empowerment of users of information: a sort of "information to the people." By thinking of information in terms of who has and who needs the information, we begin to get a different view of the information organization; in Figure $3 \mathrm{I}$ have sliced up the information pie in terms of needs of both users and the providers or facilitators: the large information universe needed by potentially everybody, such as telephone numbers; the somewhat smaller information world needed by specific individuals and groups - for example, class schedule information, or a list of library journal holdings in microbiology; and in the center the operating core of information to make the system run effectively-all of these cutting across organizational lines of libraries, academic computing, administrative computing, and more importantly, cut across lines between faculty and students, across lines between offices in different administrative areas and departments, and across multiple campuses.

I would call the Rutgers information structure that we are trying to build the interface model, where borders merge, lots of communication and negotiation goes on, we take two steps forward, one back, some changes take place quickly, others slowly, we try out some, adopt some, abandon others. This is what I see as the realistic approach to change. It is sometimes a little unnerving, since we can't always see exactly what's in front of us, even though we have a pretty good idea of the route-rather like night driving on a high speed highway.

What is the appropriate blend of library and computer facilities for a university? Will we see the end of the traditional library? To what extent will functions of libraries and computer centers eventually overlap to the point of merger? Both have been predicted, but those predictions seem to suffer from just-around-the-corner-ism: always just about to happen, but continually pushed off into the future. The paperless society has been predicted for more than twenty years; what has happened is the growth of paperless information, and proliferation of printed information as well. The computerized personal research assistant called the "Knowledge Navigator" by Apple Computer's John Sculley today bears a strong resem- 


\section{INFORMATION NEEDS \\ OF CLIENTS}

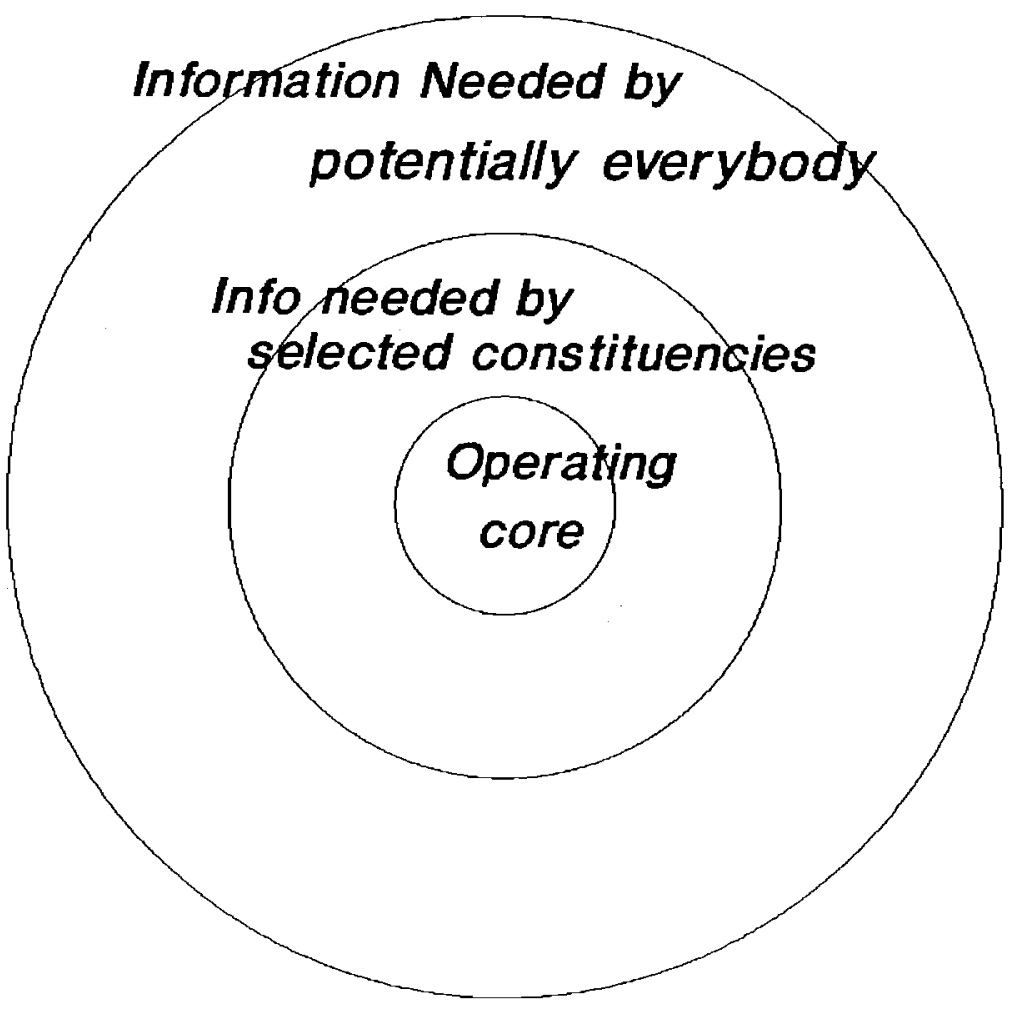

Figure 3

blance to the "Memex" posited by Vannevar Bush more than forty years ago (The Atlantic Monthly, July 1945). What is apparent is that the model for university information systems for the twenty-first century will continue to evolve for some time. Nevertheless, innovative and exciting kinds of information access are being produced and made widely available. The combination of computing services and libraries, facilitated by telecommunications, is allowing Rutgers to evolve toward the next century's concept of information services. 